\title{
Noble gas composition in Ogi and Siena meteorites
}

\author{
J T PADIA, C M NAUTIYAL, M N RAO and T R VENKATESAN \\ Physical Research Laboratory, Ahmedabad 380009 , India
}

MS received 8 June 1983

\begin{abstract}
The elemental and isotopic composition of noble gases in two chondritic meteorites which belong to documented "falls" is reported. Ogi, which belongs to the group of H-chondrites, fell in Saga, Kyushu (Japan) at 11 AM on 8 June 1741 and Siena which belongs to the group of LL-chondrites, fell in Tuscany (Italy) at 7 PM on 16 June 1794. The recovered mass of Ogi and Siena were 14.2 and $4 \mathrm{~kg}$ respectively. Their exposure ages are $13 \pm 2 \mathrm{~m} . \mathrm{y}$. and $13 \pm 3$ m.y. respectively.
\end{abstract}

Keywords. Meteorite; noble gas; nuclear track; cosmic rays; exposure age.

\section{Introduction}

The measurement of noble gas composition is important part of meteorite research and provides information on the history of meteorites, the evolution of solar system objects and on the processes induced by solar and galactic cosmic rays. Cosmic ray exposure ages are derived using the abundance of spallogenic noble gas isotope and the theoretically derived production rates. Cosmic ray exposure ages in stony meteorites are generally studied by measurements of two or more stable cosmogenic nuclides like ${ }^{3} \mathrm{He}$, ${ }^{21} \mathrm{Ne}$ and ${ }^{38} \mathrm{Ar}$. These nuclides are good cosmogenic monitors as they have low abundances in primordial noble gases and also they are not produced by the decay of longlived radionuclides. Precise exposure ages are based on ${ }^{21} \mathrm{Ne}$, because $\mathrm{Ne}$ is more retentive compared to $\mathrm{He}$ and primordial contributions in $\mathrm{Ne}$ are small. Besides it is easier to separate them than in He and Ar.

Charged-particle tracks offer another tool to decipher the cosmic ray exposure history of the meteorites. We have used them to supplement the noble gas studies.

\section{Experimental}

The noble gases were analysed in Reynolds-type ultra high vacuum all-glass mass spectrometer which was indigenously fabricated. A meteorite sample piece was wrapped in a pure $\mathrm{Al}$ foil and stored in vacuum before being dropped into a molycrucible to be heated by a RF induction heater at $1600^{\circ} \mathrm{C}$ for $1 \mathrm{hr}$. The released gases were purified using standard procedures (Rao et al 1979; Bhai et al 1978; Gopalan et al 1977). The analyser section is normally operated at $2 \times 10^{-9}$ torr and the extraction system at $3 \times 10^{-8}$ torr. All the isotopic ratios are corrected for mass discrimination and these corrections range from 0.6 to 1.47 per mass for the noble gases discussed here. The typical sensitivities of the spectrometer for different noble gases are ${ }^{22} \mathrm{Ne}=$ 
$1 \times 10^{-10} \mathrm{CCSTP} / \mathrm{mV}$ and ${ }^{132} \mathrm{Xe}=8 \times 10^{-14} \mathrm{CCSTP} / \mathrm{mV}$. $\Lambda$ source magnet was used for all gases.

\section{Results and discussion}

The elemental and isotopic composition of $\mathrm{He}, \mathrm{Ne}$ and $\mathrm{Ar}$ are given in table 1.

Noble gases originating from different sources such as solar wind, planetary gases, spallation and earth's atmosphere, have different characteristic isotopic compositions (table 2). From our results of noble gases in Ogi and Siena, it appears that all $\mathrm{He}, \mathrm{Ne}$ and Ar compositions are cosmogenic in nature. The very high $40 / 36$ ratios 7322 and 2026 in Ogi and Siena respectively suggest that most of ${ }^{40} \mathrm{Ar}$ is radiogenic. In the absence of $\mathrm{K}$ measurements, if we take $\mathrm{K}$ abundance in Ogi and Siena to be $800 \mathrm{ppm}$ (as is generally observed in stony meteorites), the ${ }^{40} \mathrm{~K}-{ }^{40}$ Ar age of Ogi and Siena turns out to be $4.5 \mathrm{~b} . \mathrm{y}$. and 3.9 b.y. respectively using the following equation which are consistent with their meteorite types $\mathrm{H}$ and $\mathrm{LL}$ respectively.

Table 1. Elemental and isotopic composition of noble gases.

\begin{tabular}{|c|c|c|}
\hline & \multicolumn{2}{|c|}{ Sample (mg) } \\
\hline & Ogi (123) & Siena (169) \\
\hline \multicolumn{3}{|c|}{ 1) Helium } \\
\hline $3 / 4$ & $0.0276 \pm 0.0006$ & $0.0202 \pm 0-0002$ \\
\hline$(4)^{*}$ & $8.96 \pm 0-36$ & $10-087 \pm 0.057$ \\
\hline \multicolumn{3}{|l|}{ 2) Neon } \\
\hline $20 / 22$ & $1.02 \pm 0.01$ & $1.62 \pm 0.01$ \\
\hline $21 / 22$ & $0.864 \pm 0.007$ & $0.819 \pm 0.007$ \\
\hline$(22)^{*}$ & $5 \cdot 314 \pm 0.054$ & $4.96 \pm 0.05$ \\
\hline \multicolumn{3}{|l|}{ 3) Argon } \\
\hline $38 / 36$ & $1 \cdot 146 \pm 0.001$ & $0.474 \pm 0.001$ \\
\hline $40 / 36$ & $7322 \pm 022$ & $2026 \pm 12$ \\
\hline$(36)^{*}$ & $0.823 \pm 0.098$ & $2.029 \pm 0.082$ \\
\hline
\end{tabular}

* He contents are given in units of $10^{-6} \propto \mathrm{STP} / \mathrm{g}$ while Ne and Ar are given as $10^{-8} \propto \mathrm{STP} / \mathrm{g}$.

Table 2. Noble gas isotopic ratios in different reservoirs*.

\begin{tabular}{lccccc}
\hline Reservoir & Helium & \multicolumn{2}{c}{ Neon } & \multicolumn{2}{c}{ Argon } \\
\cline { 2 - 5 } & $3 / 4$ & $20 / 22$ & $21 / 22$ & $38 / 36$ & $40 / 36$ \\
\hline Solar wind & $3.9 \times 10^{-4}$ & 13.5 & 0.034 & 0.186 & $\sim 1$ \\
Solar flare** & $0.01-1$ & 11.8 & 0.040 & 0.186 & $\sim 1$ \\
Planetary & $1.4 \times 10^{-4}$ & 8.2 & 0.025 & 0.192 & $\sim 1$ \\
Spallation gas & $\sim 1$ & 0.9 & 0.85 & 1.52 & $\sim 1$ \\
Air (terrestrial) & 0.0139 & 9.8 & 0.029 & 0.188 & 296 \\
\hline
\end{tabular}

* Reynolds et al (1978) and references therein.

**Venkatesan et al 1981. 
Table 3. Cosmic ray exposure ages of these meteorites.

\begin{tabular}{lcc}
\hline & \multicolumn{2}{c}{ Meteorite } \\
\cline { 2 - 3 } & Ogi & Siena \\
\hline Exposure age (m.y) & & \\
${ }^{3} \mathrm{He}$ & $11.0 \pm 2.2$ & $9.6 \pm 1.9$ \\
${ }^{21} \mathrm{Ne}$ & $13.8 \pm 1.4$ & $16.2 \pm 1 \cdot 6$ \\
${ }^{38} \mathrm{Ar}$ & $15.4 \pm 1 \cdot 6$ & $13 \cdot 8 \pm 1 \cdot 4$ \\
${ }^{40} \mathrm{~K}-{ }^{40} \mathrm{Ar}$ age (b.y) & $4 \cdot 5$ & 3.9 \\
$\mathrm{NeR}\left({ }^{22} \mathrm{Ne} /{ }^{21} \mathrm{Ne}\right)$ & $1.158 \pm 0.01$ & $1 \cdot 221 \pm 0.01$ \\
\hline
\end{tabular}

$$
{ }^{40} \mathrm{~K}-{ }^{40} \mathrm{Ar} \text { age }=t=1.8854 \times 10^{9} \times \ln \left[1+1.3315 \times \frac{{ }^{40} \mathrm{Ar}}{{ }^{40} \mathrm{~K}}\right] \text { years }
$$

where ${ }^{40} \mathrm{~K}$ in ppm units and ${ }^{40} \mathrm{Ar}$ in $\times 10^{-8} \propto \mathrm{sTP} / \mathrm{g}$ units.

The spallation of ${ }^{3} \mathrm{He},{ }^{21} \mathrm{Ne}$ and ${ }^{38} \mathrm{Ar}$ concentrations were calculated according to the procedures described by Gopalan et al (1977) and the cosmic ray exposure ages for these two chondrites were calculated after applying proper corrections and the results are given in table 3.

Recently Bhandari and Potdar (1982) calculated cosmogenic ${ }^{21} \mathrm{Ne}$ and ${ }^{22} \mathrm{Ne}$ production rates in chondrites considering the dependence on shielding depth, size of meteorite and chemical composition. Their ${ }^{21} \mathrm{Ne}$ production rates for meteoroid sizes of $25 \mathrm{~cm}$ preatmospheric radius are in good agreement with those given by Eberhardt et al (1966). They compare at the same time the production rates given by Cressy and Bogard (1976) which do not agree and are quite different. As in most cases of chondrites, data on preatmospheric sizes are not available and most chondrites have preatmospheric sizes about 10 to $25 \mathrm{~cm}$, we therefore adopt ${ }^{21} \mathrm{Ne}$ production rate given by Eberhardt et al (1966) as they fully agree with those given by Bhandari and Potdar (1982).

The ${ }^{3} \mathrm{He},{ }^{21} \mathrm{Ne}$ and ${ }^{38} \mathrm{Ar}$ ages are in good agreement within errors. The lower ${ }^{3} \mathrm{He}$ exposure ages can be ascribed to diffusion loss of helium.

In the aliquot samples of these two meteorites, large olivine crystals were carefully selected and the cosmic ray produced particle track densities were measured using standard procedures. The observed track densities are: Ogi- $78 \times 10^{5}$ tracks $/ \mathrm{cm}^{2}$ and Siena-34 $\times 10^{5}$ tracks $/ \mathrm{cm}^{2}$ (Bhandari et al 1980). The resulting TPM (tracks $/ \mathrm{cm}^{2} / \mathrm{m} . \mathrm{y}$.) values are for Ogi-5.6 $\times 10^{5}$ and Siena $2.1 \times 10^{5}$. Using these results, the preatmospheric radii of these two meteorites are determined and turn out to be about $13 \mathrm{~cm}$ and $12 \mathrm{~cm}$ respectively. Moreover these data points in TPM-NeR diagram plot between the limits set (Bhandari and Potdar 1982) and justify the above preatmospheric size estimation.

\section{Acknowledgement}

The authors thank Prof. N. Bhandari for providing these samples and for giving them valuable advice. 


\section{References}

Bhai N B, Gopalan K, Goswami J N, Rao M N and Venkatesan T R 1978 Proc. Nineth Lunar Planet. Sci. Conf. p. 1629

Bhandari N, Lal D, Nautiyal C M, Padia J T, Potdar M B, Rao M N and Venkatesan T R 1980 Meteoritics 15 265

Bhandari N and Potdar M B 1982 Earth. Planet Sci. Lett. 8116

Cressy P J Jr and Bogard D D 1976 Geochim. Cosmochim. Acta 40749

Eberhardt P, Eugster O, Geiss J and Marti K 1966 Z. Naturforsch. A21 416

Gopalan K, Goswami J N, Rao M N, Suthar K M and Venkatesan T R 1977 Proc. Eighth Lunar Planet. Sci. Conf. p. 793

Rao M N, Venkatesan T R, Goswami J N, Nautiyal C M and Padia J T 1979 Proc. Tenth Lunar Sci. Conf. p. 2009

Reynolds J H, Frick U, Neil J M and Phinney D L 1978 Geochim. Cosmochim. Acta. 421775

Venkatesan T R, Nautiyal C M and Rao M N 1981 Geophys. Res. Lett. 81143 